Volume, 14, número 1, ano, 2018.

\title{
EVASÃO ESCOLAR NA EDUCAÇÃO DE JOVENS E ADULTOS: Um olhar a partir do Colégio Estadual Normal Professor César Augusto Ceva em Ipameri - GO ${ }^{1}$
}

\author{
Rafaela Vieira Batalha ${ }^{2}$ \\ Cleber Cezar da Silva ${ }^{3}$
}

\begin{abstract}
RESUMO Esta pesquisa tem por objetivo fazer um breve contexto histórico da Educação de Jovens e Adultos (EJA), focando no processo de evasão e desistência escolar. Para tanto utiliza-se o método histórico documental e abordagem qualiquantitativa para demonstrar a constituição deste campo, tanto nacional quanto regionalmente, chegando até o Colégio Estadual Normal Professor César Augusto Ceva (CENCAC) em Ipameri-Goiás. O estudo de caso é realizado através de dados quantitativos que descortinam a realidade que se estende a várias instituições de ensino nacionais: os altos índices de evasão escolar. Avaliam-se os fatores intraescolares e extraescolares que levam a esta alta incidência de abandono da sala de aula, tentando descobrir quais são os fatores que geram esta realidade.
\end{abstract}

Palavras-chave: Educação de Jovens e Adultos. Evasão Escolar. História da Educação.

\section{EVASION IN THE EDUCATION OF YOUTH AND ADULTS: A look at the Colégio Estadual Normal Professor César Augusto Ceva in Ipameri - GO}

\begin{abstract}
This research has objective to do a brief historical context of youth and adult education (EJA) focusing on the process of dropping out of schooling. For this work, we used the documentary historical method and the qualitative-quantitative approach to demonstrate the constitution of this field - nationally and regionally, reaching the Colégio Estadual Professor César Augusto Ceva (CENCAC) in Ipameri-Goiás. The case study is done by the quantitative data. That reveal the reality that extends to several national educational institutions: the high rates of school dropout. The intraschool and extracurricular factors that lead to this high incidence of abandonment of the classroom are then evaluated, trying to find out what are the factors that generate this reality.
\end{abstract}

Key-words: Youth and Adult Education. School Evasion. History of Education.

\section{INTRODUÇÃ̃O}

\footnotetext{
${ }^{1}$ Artigo apresentado ao Programa de Pós-Graduação em Ensino de Humanidades, IF Goiano - Câmpus Urutaí, como requisito parcial para a obtenção do título de Especialista.

${ }^{2}$ Especialista pelo Programa de Pós-Graduação em Ensino de Humanidades, IF Goiano - Campus Urutaí. Graduada em Pedagogia, pela Universidade Estadual de Goiás - Câmpus Pires do Rio. E-mail: vieirarafaela2013@hotmail.com.

${ }^{3}$ Docente do Programa de Pós-Graduação em Ensino de Humanidades, IF Goiano - Campus Urutaí. Doutorando em Linguística, PPGL, UnB. E-mail: cleber.silva@ifgoiano.edu.br.
} 
Volume, 14, número 1, ano, 2018.

A Educação de Jovens e Adultos (EJA) é uma modalidade de ensino, da Educação Básica e da rede pública de ensino, que vem assegurar o direito à educação ao indivíduo, que por algum motivo teve o seu direto negado em uma determinada fase da vida (infância e/ou adolescência). É uma oportunidade que o indivíduo tem em alfabetizar-se e letrar-se, e resgatar o direito que lhe foi negado. Sendo assim, a EJA torna-se campo de estudos fecundos, pois a busca por direitos e uma vida mais digna fazem parte do crescimento do sujeito como cidadão.

O presente estudo procura analisar uma das facetas dessa modalidade, a evasão escolar. Para tanto, este trabalho é dividido em três partes: i) realiza-se uma retrospectiva histórica da Educação de Jovens e Adultos no Brasil; ii) mostra-se como esta modalidade foi implantada no estado de Goiás; iii) analisa-se os dados disponíveis sobre a evasão escolar na modalidade EJA no Colégio Estadual Normal Professor César Augusto Ceva (CENCAC), localizado na cidade de Ipameri-Goiás.

O trabalho baseia-se em dados coletados na própria instituição de ensino, por meio de observação do Projeto Político Pedagógico (2015), os dados coletados na escola são providos do Sistema Integrado de Gestão Educacional (SIGE), da Secretaria de Estado de Educação, Cultura e Esporte do Estado de Goiás. A análise é em uma abordagem qualiquantitativa. A verificação dos dados colhidos nos levam a questionar quais são os motivos da evasão escolar na EJA e a traçar possíveis respostas que possam cooperar para a erradicação e ou diminuir tal problema.

Em conformidade com os índices de alunos que se evadem da escola, principalmente, na Educação de Jovens e Adultos, pondera-se a evasão escolar como uma problemática ocasionada por distintos fatores internos ou externos à escola. No entanto, a evasão escolar não deve ser pontuada, exclusivamente, como fracasso do aluno, mas também da própria escola, que por vezes não alcança seus objetivos, especificamente, ao que se refere à produtividade do estudante

\section{DESENVOLVIMENTO}

\subsection{História da Educação de Jovens e Adultos (EJA) no Brasil}


Volume, 14, número 1, ano, 2018.

A Educação de Jovens e Adultos (EJA) é uma das modalidades previstas em lei do sistema educacional brasileiro. Ela parece ser uma criação recente e estar presente a partir do século XX, porém, essa afirmação não é verdade (ESCOTT, 2012). Se olharmos para o passado notaremos que a história das propostas educativas, as quais incluem os jovens e adultos, existem desde o período colonial.

No ano de 1549 , com o encontro entre portugueses e indígenas não vieram nas caravelas apenas soldados e administradores, estavam entre eles os padres da ordem jesuíta. Que tiveram como alvo catequisar as crianças, consideradas "ceras virgens", "papéis brancos", como se fosse possível inscrever e escrever nos índios a cultura europeia. As crianças realizariam uma substituição de gerações, pois eram elas que influenciariam seus pais.

Nos idos do século XVI essa ordem religiosa era a responsável pelo ensino na nação portuguesa e de acordos com a monarquia permitiram que viessem para o Brasil com uma função muito específica: educar os índios e fazer com que se acostumassem com os hábitos portugueses. Assim:

\footnotetext{
Quando se fala da Educação de Jovens e Adultos (EJA), deve-se abordar o período colonial em 1549, onde os jesuítas acreditavam que não seria possível converter os índios sem que eles soubessem ler e escrever. Até aqui, verifica-se a importância da alfabetização (catequização) na vida dos adultos, para que os mesmos servissem, não só para a igreja, como também para o trabalho. Os jesuítas dedicaram-se à pregação da fé católica e ao trabalho educativo. Através do trabalho de catequizar com o intuito de salvar as almas, abriram caminho para a entrada de colonizadores e, à medida que ensinavam as primeiras letras, também ensinavam a doutrina católica e os costumes europeus (SILVA; MOURA, 2013, p. 31-32).
}

Os jesuítas estiveram encarregados dessa missão até o século XVIII (1759), quando foram destituídos da função, devido a questões políticas dentro do próprio Império Português. Essa situação gerou um problema na época, pois toda a estrutura educacional montada pelos jesuítas foi desfeita, já que eles não mais a administrariam (HADDAD; DI PIERRO, 2000). Somente na época do Império Brasileiro é que se tem informações sobre uma nova estrutura de um sistema educacional brasileiro, que não dá a devida importância à educação voltada aos jovens e adultos. Destarte a isso,

No campo dos direitos legais, a primeira Constituição brasileira, de 1824, firmou, sob forte influência europeia, a garantia de uma "instrução primária e gratuita para 
Volume, 14, número 1, ano, 2018.

todos os cidadãos", portanto também para os adultos. Pouco ou quase nada foi realizado neste sentido durante todo o período imperial, mas essa inspiração iluminista tornou-se semente e enraizou-se definitivamente na cultura jurídica, manifestando-se nas Constituições brasileiras posteriores. O direito que nasceu com a norma constitucional de 1824, estendendo a garantia de uma escolarização básica para todos, não passou da intenção legal. A implantação de uma escola de qualidade para todos avançou lentamente ao longo da nossa história. É verdade, também, que tem sido interpretada como direito apenas para as crianças (HADDAD; DI PIERRO, 2000, P. 109).

A situação acima tem uma maior incidência por dois motivos: 1) a cidadania dada pela lei não é de fato estendida a todas as camadas da população nacional, deixando de fora mulheres, negros e indígenas; 2) o ato adicional de 1834 delega o dever de fornecer educação aos estados; assim, os avanços acontecem apenas nas províncias que possuem governantes interessados em dar continuidade a essa política (CURY, 2008). O caso era tão problemático que, segundo Haddad; Di Pierro (2000, p. 109), “chegaríamos em 1890 com o sistema de ensino atendendo apenas 250 mil crianças, em uma população total estimada em 14 milhões. Ao final do Império, $82 \%$ da população com idade superior a cinco anos era analfabeta".

Em 1891, temos a primeira constituição republicana brasileira, que firmou a descentralização da responsabilidade com as ações educativas para as províncias. A União ficou com o papel de cuidar do ensino secundário e superior. Porém, devemos analisar que o Brasil possuía uma população de maioria, analfabeta, sendo assim, apenas as elites alcançavam o ensino secundário e superior. Junto a isso, devido ao voto censitário, estes mesmos analfabetos não possuíam participação política.

Este período chamado de Primeira República foi cheio de reformas educativas, o que contrasta com o pouco efeito surtido por estas ações:

O censo de 1920, realizado 30 anos após o estabelecimento da República no país, indicou que $72 \%$ da população acima de cinco anos permanecia analfabeta. Até esse período, a preocupação com a educação de jovens e adultos praticamente não se distinguia como fonte de um pensamento pedagógico ou de políticas educacionais específicas (HADDAD; DI PIERRO, 2000, p. 110).

Apesar disso, como já observado, pouco se falou sobre a Educação de Jovens e Adultos, o assunto só vem à tona a partir do final da década de 1930, após a reflexão sobre o Manifesto dos Pioneiros da Educação de 1932 (CURY, 2008). Este período é caracterizado pela intenção do governo de alfabetizar as massas para que estas pudessem atender as necessidades de um país em processo de industrialização, desta forma, 
Volume, 14, número 1, ano, 2018.

Desde a Revolução de 1930, as mudanças políticas e econômicas permitiram o início da consolidação de um sistema público de educação elementar no país. A Constituição de 1934 estabeleceu a criação de um Plano Nacional de Educação (PNE), que indicava pela primeira vez a EJA com dever do Estado, incluindo em suas normas, a oferta do ensino primário integral, gratuito e de frequência obrigatória extensiva para adultos (SILVA; MOURA, 2013, p. 32).

O ano de 1940 marca uma mudança no cenário estabelecido da EJA, pois há valorização e utilização dos métodos que na década de 1960, seriam discutidos por Paulo Freire. É com essas mudanças no cenário da Educação de Jovens e Adultos, surgem iniciativas político-pedagógicas, como:

(...) a criação e regulamentação do Fundo Nacional do Ensino Primário (FNEP); a criação do Instituto Nacional de Estudos e Pesquisas (INEP); o surgimento das primeiras obras dedicadas ao ensino supletivo; o lançamento da Campanha de Educação de Adolescentes e Adultos (CEAA), e outros (SILVA; MOURA, 2013, p.32).

Todo este avanço será colocado em xeque quando o Brasil passar pelo período de retração democrática da ditadura militar. As ideias e os ideais de Paulo Freire que serviram de base para a concretização da EJA são considerados subversivos na década de 1960 e uma nova organização, o Movimento Brasileiro de Alfabetização (MOBRAL) toma a frente nesse filão educacional.

As inovações neste campo continuariam a existir e, em 1971, foi implantado o Ensino Supletivo, uma tentativa de atender a uma sociedade que está se modernizando e industrializando rapidamente, criando um mercado de trabalho cada vez mais competitivo.

Três princípios ou "ideias-força" foram estabelecidos por esses documentos que conformam as características do Ensino Supletivo. O primeiro foi a definição do Ensino Supletivo como um subsistema integrado, independente do Ensino Regular, porém com este intimamente relacionado, compondo o Sistema Nacional de Educação e Cultura. O segundo princípio foi o de colocar o Ensino Supletivo, assim como toda a reforma educacional do regime militar, voltado para o esforço do desenvolvimento nacional, seja "integrando pela alfabetização a mão-de-obra marginalizada", seja formando a força de trabalho. A terceira "ideia-força" foi a de que o Ensino Supletivo deveria ter uma doutrina e uma metodologia apropriadas aos "grandes números característicos desta linha de escolarização". Neste sentido, se contrapôs de maneira radical às experiências anteriores dos movimentos de cultura popular, que centraram suas características e metodologia sobre o grupo social definido por sua condição de classe. Portanto, o Ensino Supletivo se propunha a recuperar o atraso, reciclar o presente, formando uma mão-de-obra que contribuísse 
Volume, 14, número 1, ano, 2018.

no esforço para o desenvolvimento nacional, através de um novo modelo de escola (HADDAD; DI PIERRO, 2000, p. 117).

Em 1980, vem o avanço democrático e com ele o fim da ditadura militar. As transformações sócio-políticas geraram uma nova organização, em que a defesa da escola pública, gratuita e de qualidade ganhara força. Esse intuito é coroado pela Constituição de 1988, na qual a educação vem a ser retratada como direito de todos e dever do Estado. A educação busca desvencilhar-se dos tradicionalismos e passa a adotar práticas mais inclusivas.

Os anos 1990 trazem um retrocesso pela falta de contribuição governamental à Educação de Jovens e Adultos. Mas, já no início dos anos 2000, o governo federal firma o compromisso de priorizar este tipo de educação com o Programa Brasil Alfabetizado (SILVA; MOURA, 2013). E, de acordo com a Lei de Diretrizes e Bases Nacionais da Educação (LDB), Capítulo II, Seção V, regulamenta que:

\footnotetext{
Art. 37. A educação de jovens e adultos será destinada àqueles que não tiveram acesso ou continuidade de estudos no ensino fundamental e médio na idade própria. $\S 1^{\circ}$ Os sistemas de ensino assegurarão gratuitamente aos jovens e aos adultos que não puderam efetuar os estudos na idade regular, oportunidades educacionais apropriadas, consideradas as características do alunado, seus interesses, condições de vida e de trabalho, mediante cursos e exames.

$\S 2^{\circ} \mathrm{O}$ poder público viabilizará e estimulará o acesso e a permanência do trabalhador na escola, mediante ações integradas e complementares entre si (LDB, 1996, p.13).
}

Nota-se, que a Educação de Jovens e Adultos acompanhou as transformações políticas, sociais e econômicas do país através da história. Ela é fruto de grandes lutas e mobilizações por parte da sociedade civil nacional, que sempre buscou conquistar um ensino gratuito e de qualidade. Isso não é diferente no âmbito do estado de Goiás, como observaremos no tópico a seguir.

\subsection{A Educação de Jovens e Adultos no Estado de Goiás}

Recortamos aqui a situação histórica da formação do campo da Educação de Jovens e Adultos em Goiás. A década de 1970 se torna paradigmática para esta modalidade educativa no Estado, pois marca o surgimento do Programa de Educação Integrada (P.E.I.), que tinha como responsável por sua execução o MOBRAL. 
Volume, 14, número 1, ano, 2018.

O MOBRAL era responsável por desenvolver os programas de Alfabetização Funcional, Educação Integrada, Desenvolvimento Comunitário e Atividades Culturais. O P.E.I. tinha doze meses de duração, era realizado posteriormente a alfabetização e compreendia o compacto do conteúdo das quatro primeiras séries do $1^{\circ}$ Grau (RAIMANN, 2007). Em um primeiro momento a responsabilidade em desenvolver estes programas era a cargo da federação, porém, logo haveria mudança:

Em 1972, a responsabilidade de desenvolver o Programa de Educação Integrada foi transferida para as secretarias estaduais de educação conforme documento que dá informações gerais para o funcionamento do Curso de Alfabetização e Suplência I para a Escola Modelo (RAIMANN, 2007, p. 2).

Assim, a importância deste programa consistia no fato de ser realizado em doze meses letivos, após apenas cinco ou seis meses do curso de alfabetização - o tempo reduzido devia-se ao grande estimulo do desenvolvimento motor e da percepção, que permitia um amadurecimento mais rápido do aluno, segundo o Parecer n. ${ }^{\circ} 44 / 73$ do C.F.E., de 24 de janeiro de 1973. De acordo com Machado apud Raimann (2007, p. 2): "O referido Parecer foi sancionado no Estado de Goiás pela Resolução n 1.032, de 27 de abril de 1973, que estabeleceu normas gerais para o Ensino Supletivo".

Seria necessário então que o Estado de Goiás gerisse o chamado ensino supletivo. Na década de 1970, foi criado o Departamento de Ensino Supletivo (DESu) pelo Decreto n. ${ }^{\circ}$ 281/71 da Secretaria da Educação e Cultura do Estado de Goiás. Este órgão se tornou o responsável pelo planejamento, implantação e 
Volume, 14, número 1, ano, 2018.

implementação do Ensino Supletivo, assumindo as funções do Serviço de Educação de Adultos, conforme o previsto na Lei n5.692/71 (MACHADO, 2001).

Durante uma década, a Educação de Jovens e Adultos em Goiás esteve ligada a este departamento:

Desta forma, entre os anos de 1973 a 1983, a Educação de Jovens e Adultos em Goiás esteve ligada à modalidade de Ensino Supletivo, contando com inúmeros programas no DESu. Posteriormente, o Ensino Supletivo seria denominado por Alfabetização e Suplência I, para as quatro primeiras séries da $1^{\text {a }}$ fase do Ensino Fundamental (RAIMANN, 2007, p. 3).

Este quadro só se altera na década de 1980, com o declínio do MOBRAL, pois seus dois principais programas (Programa de Alfabetização Funcional e Programa de Educação Integrada) não haviam alcançado as metas estabelecidas para erradicação do analfabetismo. Como observado na cita abaixo:

Todavia, tanto o Programa de Alfabetização Funcional como o Programa de Educação Integrada, não conseguiram alcançar as metas estabelecidas para a erradicação do analfabetismo. (...) pesquisas sobre o período apontam dificuldades advindas da utilização dos professores leigos ou semi-qualificados (...) (MACHADO, 2001, p. 64-65).

A vistas disso, em meados da década de 1980, a situação se altera novamente devido a extinção do MOBRAL, em seu lugar fica a Fundação Escolar, que "assimilou sua estrutura e passou a apoiar técnica e financeiramente 
Volume, 14, número 1, ano, 2018.

iniciativas de governos estaduais, municipais e entidades civis" (RAIMANN, 2007, p. 3). Nos anos 1990, essa fundação e o Programa Nacional de Alfabetização e Cidadania (PNAC) se extinguem. O ano de 1993, torna-se o marco para a implantação da Educação de Jovens e Adultos, como conhecemos hoje em Goiás, segundo Raimann (2007), a documentação inicial que permite o andamento dessa modalidade no estado data-se deste período:

O primeiro documento está datado em 09/03/1993 e autoriza o funcionamento do Projeto Saturnus na escola, conforme Resolução $n^{\circ}$ 144 de 07/12/1990 do Conselho Estadual de Educação do Estado de Goiás; o outro documento, Ofício Circular n 016/93, por sua vez oferece o livro do professor "Oficina das Letras" como sugestão a ser adotada na $1^{\text {a }}$ Etapa (alfabetização) do Programa de Educação Básica (P.E.B). Tanto o Projeto Saturnus e o P.E.B. estão inseridos no programa do governo federal que, posteriormente, passa a responsabilidade do P.E.B. ao governo estadual, como se verá mais adiante no Oficio Circular n084/93 (RAIMANN, 2007, p. 1-2).

Apesar de todo este percurso, observa-se que a EJA ocupava um lugar marginal na estrutura da educação estadual até o início dos anos 2000, principalmente, por dois fatores: a má ou nenhuma formação dos professores e a visão da "facilidade" em relação ao ensino regular (a ideia da falta de cobrança e empenho necessários para a formação escolar) (MACHADO, 2001). Essa visão ainda impacta os resultados da Educação de Jovens e Adultos até os dias atuais e é isso que veremos a seguir. 
Volume, 14, número 1, ano, 2018.

\section{RESULTADOS E DISCUSSÕES}

\subsection{Evasão Escolar na EJA, no Colégio Estadual Normal Professor César Augusto Ceva em Ipameri-GO: breve estudo de caso}

O Colégio Estadual Normal Professor César Augusto Ceva (CENCAC), é uma instituição de ensino pública estadual, sediada na cidade de Ipameri-Goiás. De acordo com o Projeto Político Pedagógico (PPP), 2015, o colégio inicia suas atividades no ano de 1937, com o nome de Ginásio e Escola Normal Nossa Senhora Aparecida, sendo um colégio de Freiras. Até a década de 1970 a instituição esteve sob o comando da Igreja Católica, através das irmãs missionárias, mas, por motivos particulares à congregação necessitou encerrar as atividades do estabelecimento.

Surge um impasse, os alunos do antigo primário e ginásio poderiam ser transferidos para outras escolas, porém não havia outra instituição na região que pudesse receber as alunas do curso normal, gerando a interrupção de seus estudos. Com o apoio do Bispo Diocesano da época, Dom Liberto Pereira Lopes, realizou-se então a transferência da jurisdição religiosa para a estatal. Assim, em 8 de março de 1970, o colégio tornou-se estadual, atendendo somente alunos do Ensino Médio através do Decreto-Lei nº 153. 
Volume, 14, número 1, ano, 2018.

Desde a Lei de Diretrizes e Bases da Educação Nacional, Lei n 9.394, de

20 de dezembro de 1996, a recomendação é a de que os profissionais da educação tivessem o ensino superior completo. De acordo com esta orientação, em 1998, o CENCAC deixa de possuir o curso normal/magistério e passa a oferecer a modalidade de Ensino Médio autorizado pela Portaria SEE $n^{\circ} 7.294$, de 11 de setembro de 2002. Durante a administração municipal de 1993-1996, foram realizadas as obras da sede do CENCAC, que deixa de funcionar no prédio da sede da diocese de Ipameri - local onde ficou por 13 anos. Também em 1998 o colégio passa a contar com o turno noturno que continua em funcionamento até os dias atuais.

O CENCAC trabalha apenas com a $3^{\text {a }}$ etapa da Educação de Jovens e Adultos, que equivale ao Ensino Médio, cursado somente em dois anos, em que a $1^{\text {a }}$ série equivale ao $1^{\circ}$ ano, a $2^{\mathrm{a}}$ série ao $2^{\circ}$ ano e a $3^{\mathrm{a}}$ e $4^{\mathrm{a}}$ série ao $3^{\circ}$ ano, sendo implantado na Instituição no torno Noturno a partir do ano de 2000. A realidade dos alunos pertencentes a EJA no CENCAC, não se difere muito de outros lugares, pois:

\footnotetext{
As classes da EJA também recebem sujeitos com nível cultural e educacional diferenciado, o que faz do espaço da sala de aula um ambiente rico e marcado pela diversidade. Além disso, os alunos de EJA em função de fracassos anteriores possuem, muitas vezes, uma baixa autoestima; portanto precisam ser motivados, e o educador deverá buscar diferentes maneiras de promover e despertar o interesse e o entusiasmo e acima de tudo mostrar a esses alunos que é possível aprender (SILVA (2015, p. 26741).
}

Essa realidade é mostrada no PPP do CENCAC, e, quando é revelada a faixa etária dos alunos da EJA - entre 18 a 60 anos, fica visível a diversidade presente no estabelecimento de ensino. Apesar de o PPP afirmar que não há grandes diferenças nas condutas, vestuário e preferências, acreditamos que o conflito inter-geracional, provavelmente, está presente tanto nas relações discentes, quanto nas relações entre alunos e professores. 
Volume, 14, número 1, ano, 2018.

Frente à realidade apresentada nas bases teóricas sobre o tema da evasão escolar, buscou-se no decorrer deste estudo, por meio da revisão de literatura, ainda em discussão, e com os dados disponibilizados pelo CENCAC. Dados estes contidos na Planilha Diagnóstica Final das Instituições Escolares, documento gerado pelo sistema (SIGE), da Secretaria de Estado de Educação, Cultura e Esporte do Estado de Goiás, por meio dos dados reunidos na Subsecretaria Regional de Educação de Pires do Rio, em seu Núcleo Pedagógico.

A partir dos dados coletados, em relação a quantidade de alunos matriculados, aprovados, transferidos, reprovados, em progressão parcial, evadidos e desistentes, na EJA no ano de 2016, procurou-se a melhor forma para visualizar o que é apresentado. Escolhemos os gráficos, para melhor representação e análise dos números, assim os apresentamos: i) gráfico 1, os dados do diagnóstico final das turmas da EJA no ano de 2016. O que se fez foi um gráfico de barras com linha de tendência, tendo como parâmetro os números de evasão e desistência, isso foi feito para que se pudesse observar de forma clara a progressão destes dados ao longo das séries em um mesmo ano; ii) gráfico 2 , os dados referentes aos alunos da $1^{\text {a }}$ série da EJA; iii) gráfico 3, os dados referentes aos alunos da $2^{\text {a }}$ série da EJA; iv) gráfico 4 , os dados referentes aos alunos da $3^{\text {a }}$ série da EJA; v) gráfico 5 , os dados referentes aos alunos da $4^{\text {a }}$ série da EJA. Assim, cabe mencionar, que os números e percentuais observados com maior profundidade são os referentes a evasão escolar, como apresentamos nos gráficos a seguir.

Gráfico 1 - Gráfico por série baseado na Planilha Diagnóstica Final do CENCAC, 2016. 
Volume, 14, número 1, ano, 2018.

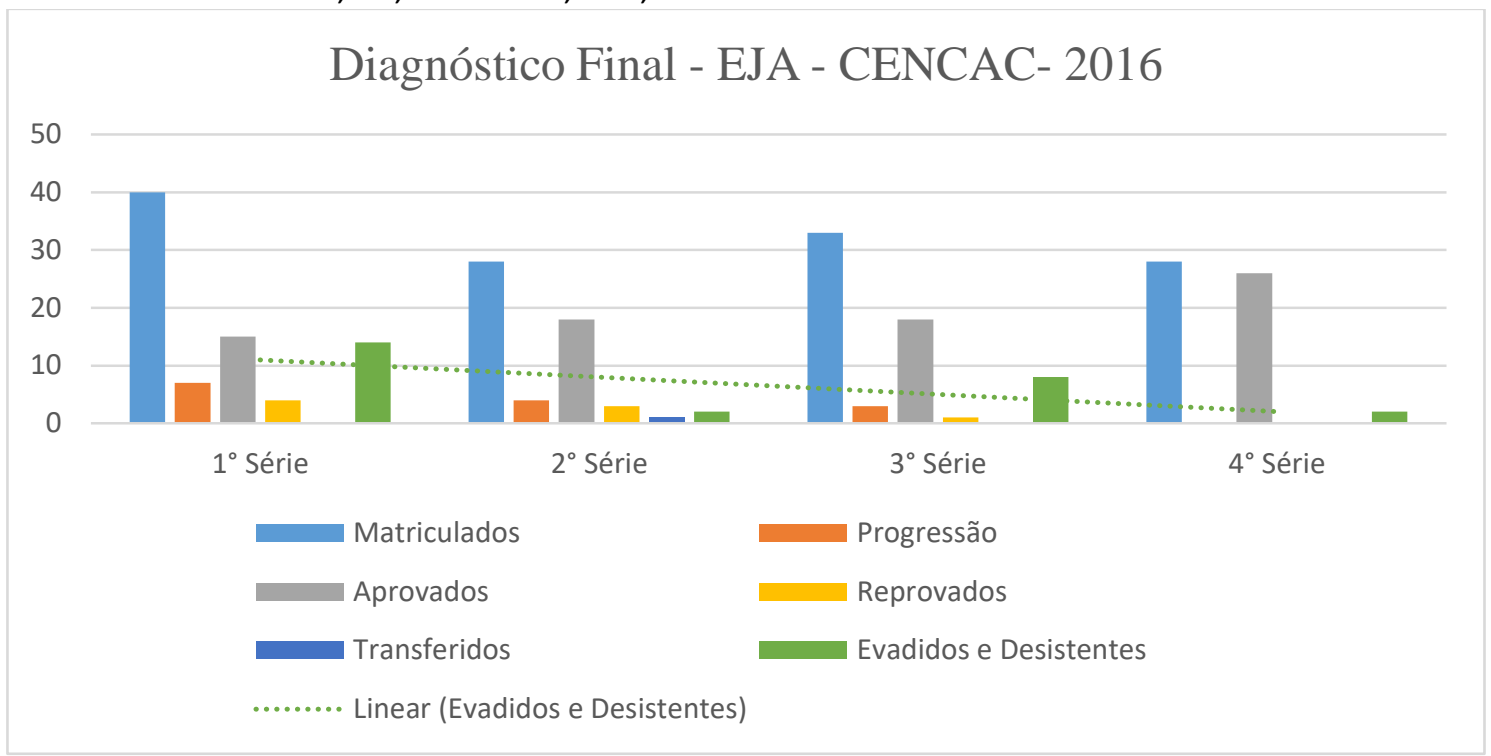

Fonte: BATALHA; SILVA, 2017.

Observa-se na linha descendente que a evasão e desistência tendem a diminuir ao longo das séries da EJA, $3^{\text {a }}$ fase, no CENCAC. É notável o declínio do número de matrículas no decorrer dos períodos letivos, consequentemente, os indivíduos que acabam por cursar e concluir essa etapa são aqueles mais resilientes ou os que encontram apoio durante a jornada escolar.

E, analisar a evasão escolar exige de nós um olhar distinto aos alunos, já que, devemos considerar as suas trajetórias de vida. Destarte a isso, observa-se que:

\footnotetext{
Os índices de abandono na EJA, que tenta se escolarizar ainda que com tímidas flexibilizações, refletem que nem com um estilo escolar mais flexível eles e elas conseguem articular suas trajetórias de vida e as trajetórias escolares. Os impasses estão postos. Como equacionar o direito à educação dos jovens e adultos populares e o dever do Estado? (MIGUEL ARROYO,2005, p.46).
}

Arroyo (2005) aponta que é um desafio da escola das camadas populares, a qual representa o Estado na oferta do direito à educação. Ainda, há de se pensar que a escola se constitui como uma realidade recente, em fase de construção. Frente a tantos anos de exclusão, como agregar os alunos para thes oferecer uma educação escolar de qualidade, tendo em vista a sua trajetória de vida e escolar? Ao pensar desta forma, nos cabe mencionar, "que a escola precisa ir além dos conhecimentos escolares e procurar um aprofundamento no 
Volume, 14, número 1, ano, 2018.

reconhecimento das necessidades dos alunos, principalmente no que diz respeito à inserção no mundo do trabalho" (FARIA, 2013, p. 58).

É necessário realizar uma análise dos dados coletados, série a série, o que evidencia o já mencionado, anteriormente, em relação ao declínio da evasão e desistência nos períodos subsequentes.

Gráfico 2 - Gráfico com o compilado dos dados da $1^{\text {a }}$ série, baseado na Planilha Diagnóstica Final do CENCAC, 2016.

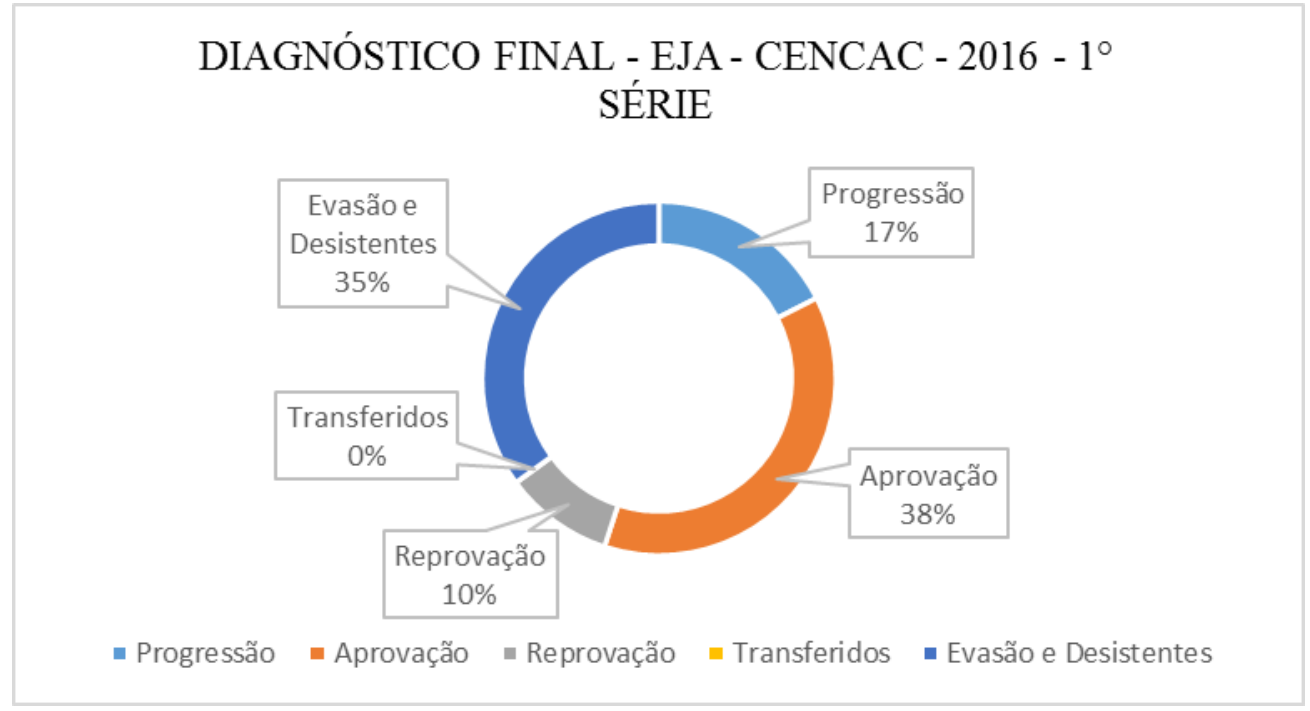

Fonte: BATALHA; SILVA, 2017.

Durante a primeira série, $35 \%$ dos alunos matriculados evadiram ou desistiram dos estudos. Enquanto $10 \%$ dos alunos matriculados foram reprovados e $17 \%$ ficaram em progressão educacional (progressão parcial). Por conseguinte, o índice de aprovação foi de apenas $38 \%$, sendo que o índice de alunos sem aproveitamento completo foi de $62 \%$, muito superior ao de aprovação.

A evasão escolar acontece no momento em que o aluno deixa de frequentar as aulas, afastando-se das atividades escolares durante o ano letivo. Contudo, a escola como instituição formadora e socializadora, com profissionais capacitados tem o compromisso de fomentar estratégias pedagógicas condizentes com a realidade do aluno evadido, a fim de resgatá-lo e assegurar a sua permanência até que finalize os seus estudos. E, de acordo com Gagno e Portela (2013), a garantia do acesso e permanência com êxito do aluno da EJA, deve ser meta 
Volume, 14, número 1, ano, 2018.

de toda a sociedade, e para isso é necessário que seja respeitado todas as diferenças, que são trazidas por esses estudantes.

Segundo Arroyo (2006, p. 23), não se pode enxergar os jovens que frequentam as classes da EJA como aqueles que não tiveram êxito no ensino regular, ou seja, "alunos evadidos, reprovados, defasados, alunos com problemas de frequência, de aprendizagem, não concluintes da $1^{\mathrm{a}}$ à $4^{\mathrm{a}}$ ou da $5^{\mathrm{a}}$ a $8^{\mathrm{a}}$. E, de acordo com isso trazemos mais alguns dados para análise.

Gráfico 3 - Gráfico com o compilado dos dados da 2a série, baseado na Planilha Diagnóstica Final do CENCAC, 2016.

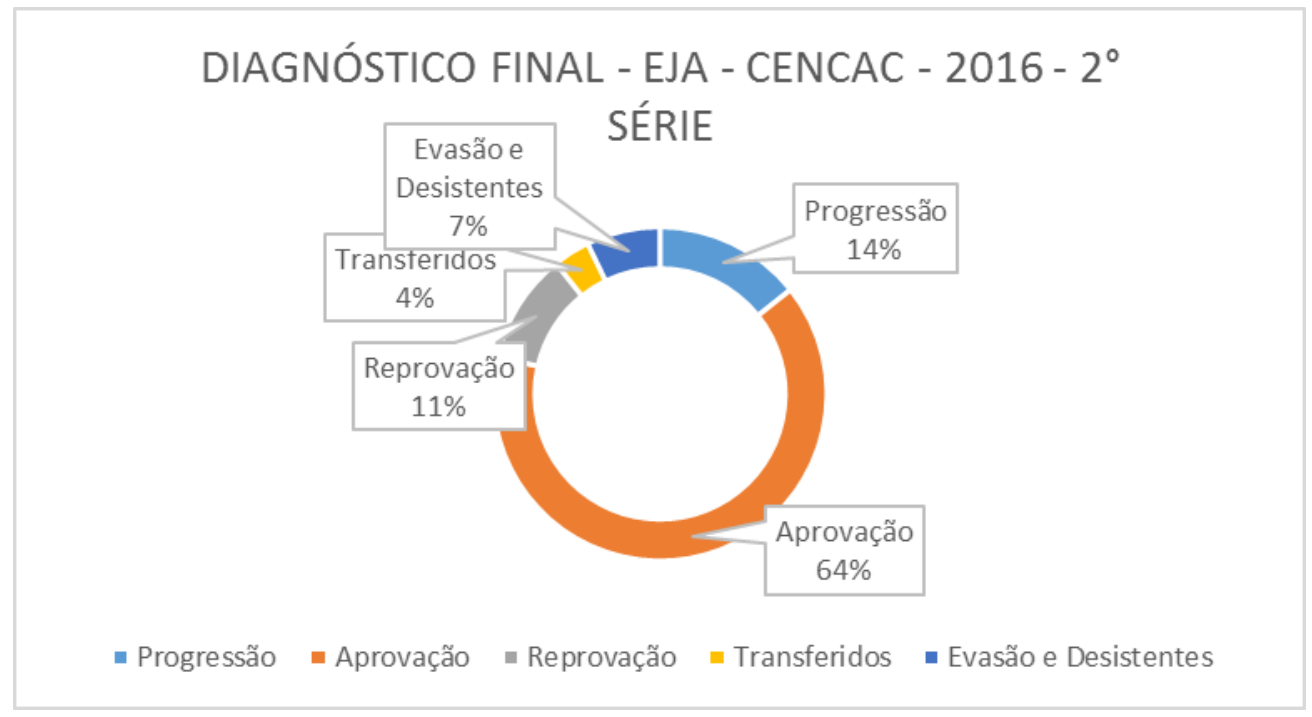

Fonte: BATALHA; SILVA, 2017.

Observando os dados da segunda série nota-se uma queda considerável no índice da evasão e desistência: apenas 7\% dos alunos entraram nessa categoria. Quanto aos outros 14\% dos alunos ficaram de progressão, $11 \%$ foram reprovados e $4 \%$ transferidos. A aprovação para esta série foi de $64 \%$ versus $36 \%$ dos alunos que não obtiveram aproveitamento completo.

Podermos aqui, coadunar com Arroyo (2006), que fala de uma nova reconfiguração da EJA, em que os jovens devem serem vistos, primeiramente, em suas potencialidades e não nas suas fraquezas e carências. Entretanto, abaixo trazemos uma cita que indica alguns motivos da entrada dos jovens na EJA: 
Volume, 14, número 1, ano, 2018.

A evasão e a repetência, que ocasionam a defasagem entre a idade e série; da busca pela certificação escolar oriunda da necessidade de trabalhar; da dificuldade de acesso; da ausência de motivação para o retorno a escola, entre outras (CARVALHO, 2012, p. 1).

No entanto, observa-se que o estigma do estudante da EJA é daquele que não teve sucesso no ensino regular. Já para Arroyo (2006), as carências escolares dos indivíduos que chegam à EJA mostram, na verdade, as necessidades sociais que são arremessados. Apesar das adversidades, eles procuram a instituição escolar com a tentativa de encontrar caminhos e construir novos percursos. Além disso, esses alunos trazem uma bagagem de conhecimento de sobrevivência nas adversidades da vida, que Arroyo (2006, p. 25) chama de "múltiplos espaços deformadores e formadores", do qual os jovens participam.

Gráfico 4 - Gráfico com o compilado dos dados da $3^{\text {a }}$ série, baseado na Planilha Diagnóstica Final do CENCAC, 2016.

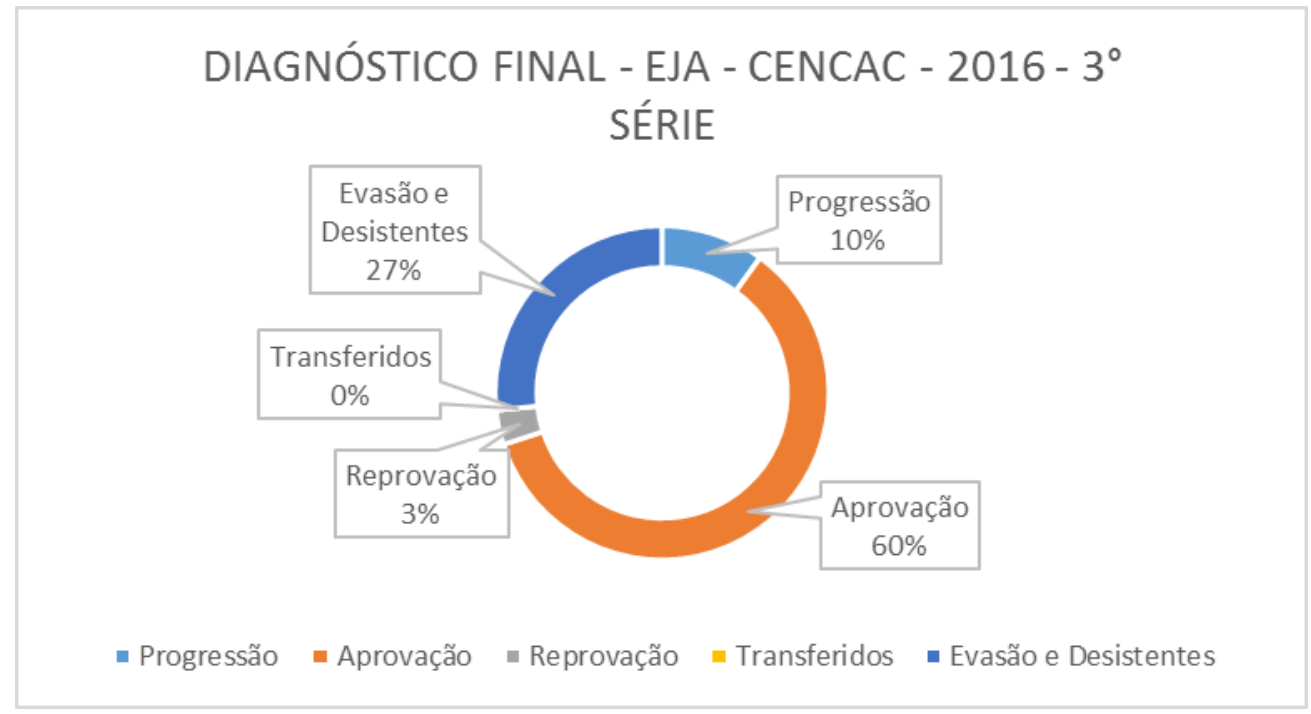

Fonte: BATALHA; SILVA, 2017.

No gráfico 4, nos é apresentado uma retomada do crescimento no índice de evasão e desistência (27\%). Enquanto, 10\% dos alunos ficaram em progressão, 3\% foram reprovados e $60 \%$ aprovados. Ainda não fica claro porque houve maior evasão, já que este é o início do último ano de estudos para aqueles que querem concluir o Ensino Médio na modalidade EJA. Eventualmente, para chegar a dados precisos sobre os reais motivos que levaram aos alunos à evasão e à desistência, seria necessário uma pesquisa in loco, a fím de construir 
Volume, 14, número 1, ano, 2018.

considerações, que explicaria o alto índice de evasão e desistência na referida turma, visto que, o estudo analisa apenas dados referente ao ano letivo de 2016.

No entanto, hipoteticamente, fazemos menção a um fator significativo da instituição de ensino ao que se reporta a evasão escolar do aluno, isso de com Brandão (1993, p.38), que argumenta: "a evasão e repetência longe está de ser fruto de características individuais dos alunos e suas famílias. Ao contrário, refletem a forma como a escola recebe e exerce ação sobre os membros destes diferentes segmentos da sociedade". Pensar na permanência e êxito do aluno da EJA na escola, é reconhecer a forma de como a instituição enxerga e lida com os problemas dos mesmos, já que, cada um traz consigo histórias de vidas distintas e fragilidades específicas.

Gráfico 5 - Gráfico com o compilado dos dados da $4^{\mathrm{a}}$ série, baseado na Planilha Diagnóstica Final do CENCAC, 2016.

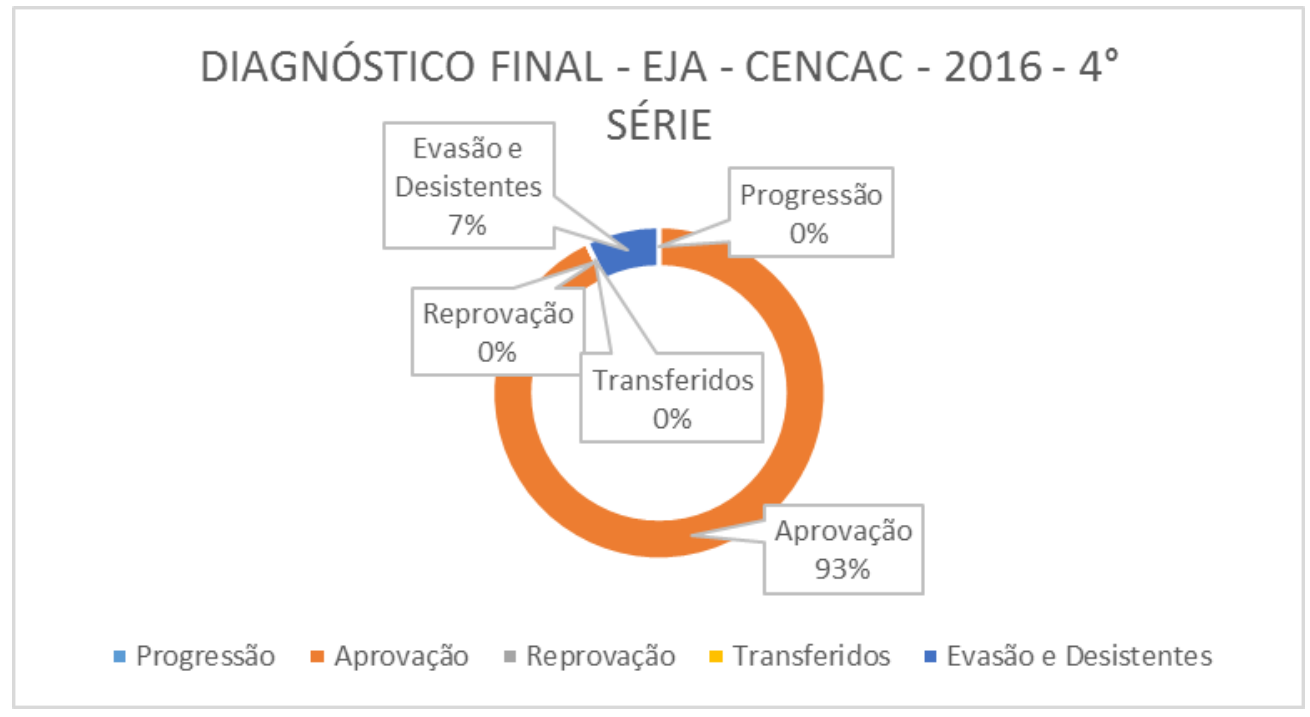

Fonte: BATALHA; SILVA, 2017.

A última série a ser analisada ( $4^{\mathrm{a}}$ série) possui peculiaridades, por se tratar do momento final dessa fase da pesquisa, não tendo nenhuma transferência e reprovação. Porém, continuou ocorrendo evasão e desistência que representaram $7 \%$ do total de matriculados, mas os dados de aprovação são significativos, pois nas séries anteriores, nenhuma atingiu a média igual ou superior a esta: $93 \%$ do número de alunos matriculados.

No total, no ano de 2016, no CENCAC na terceira fase da EJA 27\% dos alunos desistiram de dar continuidade aos seus estudos, $8 \%$ deles foram reprovados, $15 \%$ 
Volume, 14, número 1, ano, 2018.

necessitaram de progressão em alguma disciplina, $1 \%$ foi transferido e $49 \%$ foram aprovados. Como já mencionado, anteriormente, para conseguir respostas a vista de compreensão desse índice, seria necessário uma pesquisa in loco, para identificar os principais fatores que levaram os alunos a se evadirem da escola.

Por fim, o que nos chama a atenção, no geral, em 2016, é o índice de alunos que não conseguiram aproveitamento completo do curso oferecido, o qual foi quase equivalente ao dos que conseguiram: $51 \%$ versus $49 \%$. No gráfico abaixo revelamos tais dados.

Gráfico 6 - Gráfico com o compilado dos dados totais da EJA baseado na Planilha Diagnóstica Final do CENCAC, 2016.

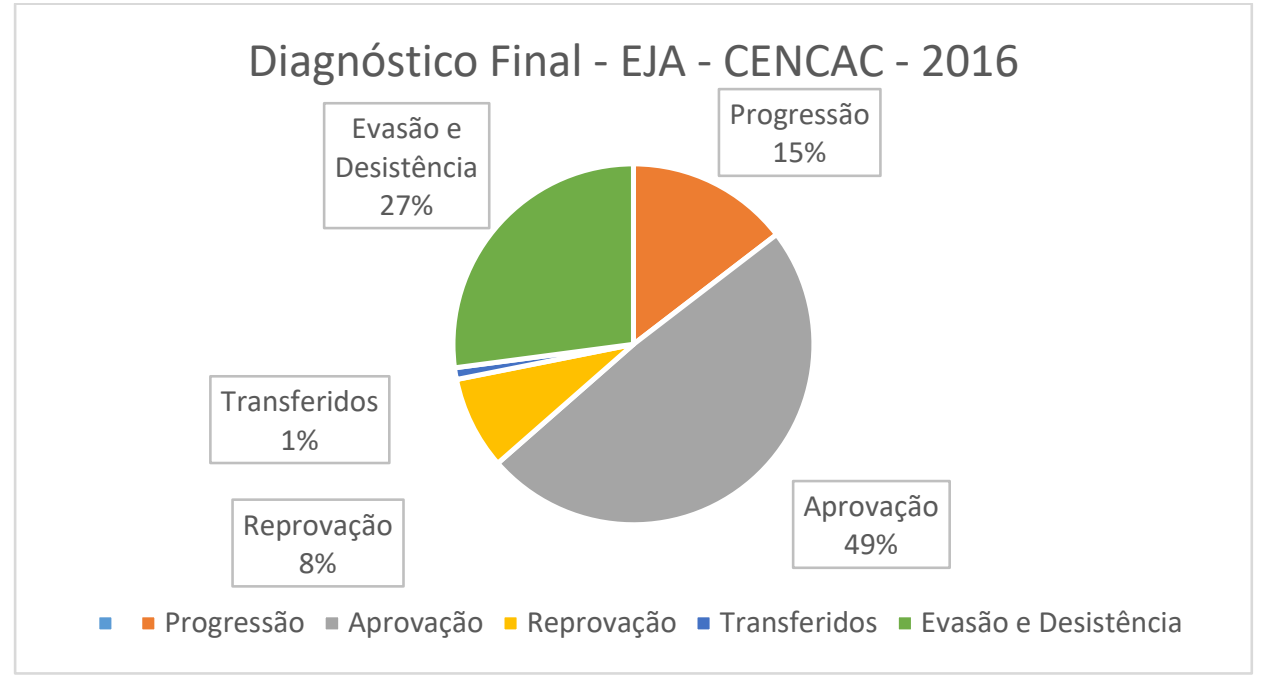

Fonte: BATALHA; SILVA, 2017.

Segundo SILVA (2015, p. 26745): "Evasão escolar é o abandono da escola antes da conclusão de uma série ou de um determinado nível em uma modalidade de ensino". É dever da escola por determinação da Lei de Diretrizes e Bases da Educação, garantir que os alunos concluam seus estudos. Porém, o que é orientado por essas diretrizes nem sempre é fácil de se realizar. Como observamos a partir dos dados apresentados, a evasão escolar é uma realidade e diversos são os fatores que podem ser causas para o abandono da escola. Aqui adotaremos como motivações as instancias político-social, motivacional e técnico administrativo/pedagógico como fatores escolares, também, os fatores de ordem social, familiar e trabalho, como marcadores para o fato da evasão escolar. 
Volume, 14, número 1, ano, 2018.

A falta de políticas públicas que priorizem a qualidade do ensino na modalidade EJA é um dos impasses para a consolidação dessa etapa na educação. Dito anteriormente, muitas vezes a Educação de Jovens e Adultos é vista como de segunda categoria, o que faz com que alunos e professores desacreditem em seu potencial transformador. Assim, fatores motivacionais estão intrinsicamente ligados a essa visão, e, também, uma certa falta de diferenciação nas propostas pedagógicas do ensino regular para a EJA. Porém, além destes fatores existem aquelas situações que influenciam diretamente na vida dos alunos, como, a falta de tempo, por causa do trabalho e até mesmo por motivos pessoais dentre outros motivos.

\footnotetext{
É fato que, muitos são os fatores extraescolares que contribuíram para a desistência desses alunos como: falta de interesse do aluno, situação de risco no percurso que fazem até a escola trabalha para manter o sustento próprio e da família, falta de incentivo, migração para outro município à procura de oportunidade de trabalho, falta de uma relação interpessoal saudável dentro da escola, reprovação escolar, gravidez (filho), casamento (SILVA, 2015, p. 26747).
}

Contudo, é evidente, que além dos números aqui apresentados, é necessário uma pesquisa in loco para compreender os reais motivos que corroboram com o processo de evasão e desistência, a fim de buscar alternativas para amenizar ou solucionar os problemas advindos da evasão escolar no Colégio Estadual Normal Professor César Augusto Ceva.

\section{CONSIDERAÇÕES FINAIS}

O presente artigo buscou realizar o estudo de um caso preliminar sobre a temática da evasão escolar, na modalidade EJA, no Colégio Estadual Normal Professor César Augusto Ceva, na cidade de Ipameri-GO. Para tanto, o caminho percorrido foi subdividido em dois momentos: no primeiro discorremos sobre a história desta modalidade de ensino, tanto no Brasil como no estado de Goiás e, no segundo momento buscamos analisar os dados obtidos através do sistema (SIGE), da Secretaria de Estado de Educação, Cultura e Esporte, referente ao ano letivo de 2016.

A análise aqui apresentada se manteve no campo qualiquantitativo, os dados cedidos foram considerados a partir da construção de gráficos, que ajudaram a visualizar de maneira mais clara como tem sido drástica a evasão escolar na Educação de Jovens e Adultos. Sendo 
Volume, 14, número 1, ano, 2018.

assim, este estudo se mostra mais exploratório e abre a possibilidade para novas abordagens e pesquisas neste campo, principalmente, para que se possa confirmar hipóteses suscitadas através da literatura sobre o tema e a apreciação de dados, por meio de pesquisas in loco e com uma vertente, especificamente, qualitativa.

De acordo com Ireland (2009) diversas são as variáveis que interferem no processo da evasão escolar. E, muitas vezes, o estudante não deixa a escola voluntariamente, isso ocorre por causa da família ou do trabalho. Também, existe a questão da qualidade do curso oferecido, desta forma seria necessário repensar a forma de ensino e se supre a necessidade do educando, inclusive para a área do trabalho. Isso indica, que falta pensar a EJA nas demandas de aprendizagem dessa clientela específica.

Assim, segundo Faria (2013, p.59) “ as políticas de ensino profissionalizante via EJA precisam ser ampliadas, tendo em vista o atendimento a um maior número de alunos e ao aumento das opções de cursos que atraem o público jovem”. É importante conhecer que a maioria dos estudantes que procuram concluir a educação formal, também carecem de qualificação profissional, e por isso, deve-se articular a formação deles com a educação continuada.

Os dados analisados nesta pesquisa, ainda são alarmantes, considerando principalmente, que, em todas as séries ocorreu a evasão, pois na primeira série atingiu a 35\%, sendo reduzida ao longo dos anos, chegando a última série com $7 \%$. Uma possibilidade de pesquisa é entender porque a evasão é tão grande no primeiro ano, focando principalmente nas dificuldades encontradas por estes alunos para dar prosseguimento ao curso. Outro índice interessante é o de progressão. Excluindo-se a última série a progressão nunca deixa de estar igual ou acima de $10 \%$, o que demonstra as dificuldades enfrentadas tanto pelos docentes como pelos discentes são persistentes. Seria ideal analisar em quais disciplinas o índice de progressão incide e quais as causas dessa realidade. A mesma metodologia deve também ser aplicada aos casos de reprovação que, em números gerais, chega a $8 \%$.

Os resultados parciais desta pesquisa é a constatação de que a evasão escolar na EJA é um grave problema e precisa além de políticas públicas de qualidade e do envolvimento da sociedade. Os fatores extraescolares fazem parte da sintomática mudança social da pósmodernidade e das necessidades cada vez mais vorazes do capitalismo pós-industrial. Assim, 
Volume, 14, número 1, ano, 2018.

criar uma sociedade mais justa é criar um ambiente, em que a educação possa não ser apenas plantada, mas sim crescer e florescer na vida das pessoas.

\section{REFERÊNCIAS}

ARROYO, Miguel González. Educação de Jovens-adultos: um campo de direito e de responsabilidade pública. In: SOARES, Leôncio; GIOVANETTI, Maria Amélia Gomes de Castro; GOMES, Nilma Lino (Org). Diálogos na educação de jovens e adultos. 2 ed. Belo Horizonte: Autêntica, 2006.

Educação de jovens e adultos: um campo de direitos e de responsabilidade pública. Caderno de textos: $1^{a}$ Conferência Municipal de Educação de Contagem - MG. p. 39-56. Contagem, MG. 2005.

BRANDÃO, Zaia. O estado da arte da pesquisa sobre evasão e repetência no ensino de $1^{\circ}$ grau no Brasil. Revista Brasileira de Estudos Pedagógicos, v. 64, $\mathrm{n}^{\mathrm{o}}$ 147, p.38-69, maio/agos.1993.

BRASIL. Ministério de Educação e Cultura. LDB - Lei no 9394/96, de 20 de dezembro de 1996. Estabelece as diretrizes e bases da Educação Nacional. Brasília: MEC, 1996.

CARVALHO, Roseli Vaz. A juvenilização da EJA: quais práticas pedagógicas? 2012. Disponível em: 〈http://www.horacio.pro.br/oldsite/fmp/ped/2011-2/eja/GT18-5569--Int.pdf>. Acesso em: 20 dez. 2017.

CURY, Carlos Roberto. Sistema Nacional de Educação: desafio para uma educação igualitária e federativa. Educ. Soc. Campinas, vol. 29, n. 105, p. 1187-1209, set./dez. 2008. Disponível em: <http://www.cedes.unicamp.br> Acesso em: 06 jun. 2017.

ESCOTT, Clarice Monteiro. História Da Educação Profissional No Brasil: Políticas Públicas E O Novo Cenário De Formação De Professores Nos Institutos Federais De Educação, Ciência E Tecnologia. IX Seminário Nacional de Estudos e pesquisas "História, Sociedade e Educação no Brasil", Universidade Federal da Paraíba - João Pessoa, Anais Eletrônicos. $2012 . \quad$ Disponível em: <http://www.histedbr.fe.unicamp.br/acer_histedbr/seminario/seminario9/PDFs/2.51.pdf>. Acesso em: 04 jul. 2017.

FARIA, Roselita Soares de. Evasão e permanência na EJA: por um trabalho de qualidade na gestão de uma escola da rede municipal de Belo Horizonte. 117 f. Dissertação (Mestrado Profissional em Gestão e Avaliação da Educação Pública). Universidade Federal de Juiz de Fora, Faculdade de Educação/CAEd. Programa de Pós-Graduação em Gestão e Avaliação da Educação Pública, 2013. 
Volume, 14, número 1, ano, 2018.

GAGNO, Roberta Ravaglio e PORTELA, Mariliza Simonete. Gestão e Organização da Educação de Jovens e Adultos: Perspectiva de Prática Discente. São Paulo, 2003.

HADDAD, Sérgio; DI PIERRO, Maria Clara. Escolarização de jovens e adultos. Revista brasileira de educação. Rio de Janeiro, $\mathrm{n}^{\circ}$ 14, p. 108-130, 2000. Disponível em: <http://www.scielo.br/pdf/rbedu/n14/n14a07.pdf >. Acesso em: 20 jun. 2017.

IRELAND, Timothy. Revista Nova Escola, ed. 223, jun. 2009.

MACHADO, Maria Margarida. A política de formação de professores que atuam na educação de jovens e adultos em Goiás na década de 1990. 2001. $231 \mathrm{f}$. Tese (Doutorado em Educação) - Programa de Estudos Pós-graduados em Educação: História, Política, Sociedade. São Paulo, 2001.

NUNES, Luana Rodrigues; SILVA, Bruna Lorrany; SILVA, Danielly Cardoso. A educação de jovens e adultos em Goiás revelada por documentos e pela memória dos sujeitos envolvidos. In: Encontro Regional de História Anpuh - GO, 11. 2015. Cidade de Goiás. Anais... Cidade de Goiás, $2015 . \quad$ Disponível em: <http://www.anais.ueg.br/index.php/anpuhgo/article/view/4189> Acesso em: 21 jun. 2017.

Projeto Político Pedagógico. Colégio Estadual Normal Professor César Augusto Ceva. Ipameri-GO, 2015.

RAIMANN, Elizabeth Gottschalg. A educação de jovens e adultos em Goiás: uma retrospectiva histórica. In: Congresso Internacional de História. 5, 2007, Jataí. Anais... Jataí, 2007.

Disponível em: $<$ http://www.congressohistoriajatai.org/anais2007/doc\%20(19).pdf > Acesso em: 05 jul. 2017.

SILVA, Hellen Tânia Rodrigues da; MOURA, Tânia Mara Souza. Educação de jovens e adultos - EJA: desafios e práticas pedagógicas. Revista Eletrônica Univar. On-line, Vol 3, p. $31 \quad-36,2013.20$ Disponível <revista.univar.edu.br/index.php/interdisciplinar/article/view/53/41> Acesso em: 15 jun. 2017.

SILVA, Hérica Fontes da. As causas da evasão escolar: um estudo de caso numa unidade de ensino da rede municipal de Itupiranga - Pará nos anos de 2013 e 2014. In: Congresso Nacional de Educação. 12, Anais..., Paraná, 2015. 